\title{
ANALISIS PENGARUH KUALITAS SISTEM, KUALITAS INFORMASI DAN PERCEIVED USEFULLNESS TERHADAP KEPUASAAN PENGGUNA APLIKASI E-BENEFIT DALAM UPAYA MENINGKATKAN KINERJA KARYAWAN PADA PT ASURANSI JIWA CENTRAL ASIA RAYA DI JAKARTA
}

\section{Bugi Tri Harso, Dino Arletta, Kusumo Adi}

Fakultas Ekonomi dan Bisnis Universitas Budi Luhur Jakarta, Indonesia

Email: bugitriharso24@gmail.com, dienoarletta23@gmail.com, kusumoadi@gmail.com

\begin{abstract}
Abstrak
Pandemi Covid-19 memukul banyak sektor usaha, tak terkecuali perusahaan asuransi, sehingga Manajemen berusaha mempertahankan dan meningkatkan kinerja perusahaan dengan mengevaluasi kinerja karyawannya dimasa pandemi Covid-19 dalam penggunaan teknologi informasi aplikasi E-BENEFIT. Penelitian ini dilakukan dengan alasan mencari tahu ketidakpuasan dari pengguna terhadap sistem tersebut seperti informasi yang dibutuhkan masih salah, masih ada error bugs, butuh waktu lama saat menarik data atau mengupload dokumen kedalam sistem dan kurangnya fitur yang dibutuhkan oleh karyawan (user). Penelitian ini menggunakan pendekatan kuantitatif dimana masalah dan hipotesis telah ditentukan dan dijabarkan diawal, tahap selanjutnya melakukan survey dengan menyebarkan kuisioner kepada 50 orang karyawan PT Asuransi Jiwa Central Asia Raya pengguna aplikasi E-BENEFIT untuk mendapatkan data. Data yang dikumpulkan dianalisis dan pengujian hipotesis dilakukan dengan metode korelasi, regresi dan analisis jalur (path analysis) dengan persyaratan uji validitas/reliabilitas dan statistik deskriptif dengan menggunakan software SPSS. Hasil dari penelitian ini dapat mengetahui bahwa variabel Kualitas Sistem, Kualitas Informasi, Perceived Usefulness berpengaruh positif terhadap kepuasan pengguna dan variabel kepuasan pengguna berpengaruh positif terhadap kinerja individu karyawan.
\end{abstract}

Kata Kunci: kualitas sistem; kualitas informasi; perceived usefulness; kepuasan pengguna; kinerja individu

\section{Abstract}

The Covid-19 pandemic hit many business sectors, including insurance companies, so Management is working to maintain and improve the company's performance by evaluating the performance of its employees during the Covid-19 pandemic in the use of E-BENEFIT application information technology. This research is conducted on the basis of knowing dissatisfaction from users with the system such as the information needed is still wrong, there are still bug errors, it takes a long time when pulling data or uploading documents into the system and lack of features needed by employees (users). This study uses a quantitative approach where problems and hypotheses have been determined and spelled out at the beginning, the next stage of conducting a survey by distributing questionnaires to 50

\begin{tabular}{ll}
\hline How to cite: & Harso. B.T, Arletta. D., \& Adi, K., (2021) Analisis Pengaruh Kualitas Sistem, Kualitas Informasi \\
& dan Perceived Usefullness, Syntax Idea, 3(11), https://doi.org/10.36418/syntax-idea.v3i10.1521 \\
E-ISSN: & 2684-883X \\
Published by: & Ridwan Institute
\end{tabular}


employees of PT Asuransi Jiwa Asia Tengah Raya users of the E-BENEFIT application to obtain data. The collected data is analyzed and hypothesis testing is conducted by correlation analysis methods, regressions and pathways with descriptive validity and statistical test requirements using SPSS software. The results of this study can be found that the variables of System Quality, Information Quality, Perceived Usability positively affect user satisfaction and user satisfaction variables positively affect the individual performance of employees.

Keywords: system quality; information quality; perceived usefulness; user satisfaction; individual performance

\section{Received: 2021-09-22; Accepted: 2021-10-05; Published: 2021-10-20}

\section{Pendahuluan}

Pandemi Covid-19 memukul banyak sektor usaha, tak terkecuali perusahaan asuransi. Hal ini menjadi tantangan bagi manajemen untuk memutar otak dan mengatur strategi melaju ditengah krisis. Sehingga manajemen harus tetap menjaga kinerja karyawannya untuk tetap memberikan pelayanan yang terbaik terhadap nasabah, agar proses bisnis yang berjalan saat ini tidak terganggu.

Otorisasi Jasa Keuangan (OJK) memperkirakan, akan terjadi tiga hal di masa pandemi hingga Covid-19 berakhir. Pertama, terjadi pengurangan bisnis asuransi (demand reduction), Asosiasi Asuransi Jiwa Indonesia (AAJI) mencatat pertumbuhan premi pada 2020 terkoreksi 6,1\% secara tahunan dari Rp199,87 triliun di 2019 menjadi Rp187,59 triliun.

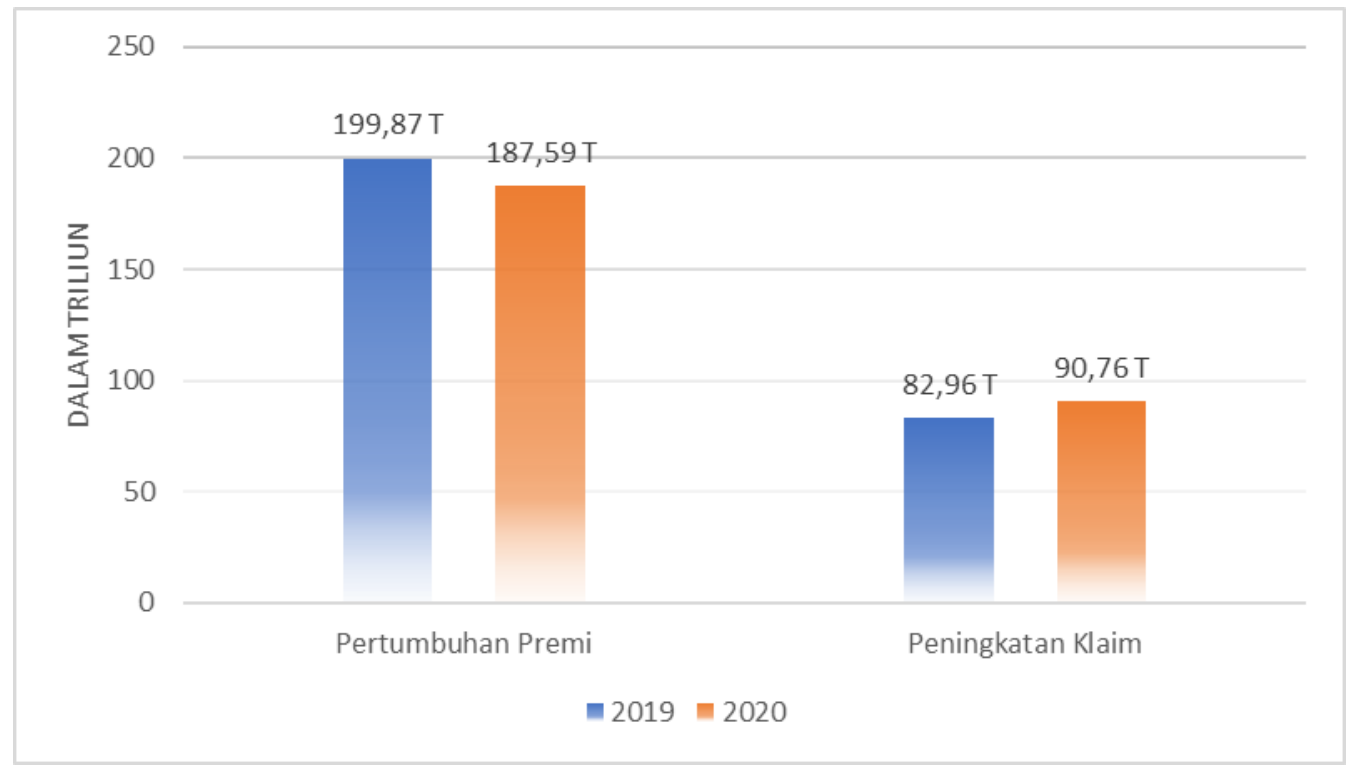

Gambar 1

Grafik Pertumbuhan Premi Tahun 2019-2020

Kedua, terjadi peningkatan klaim karena para nasabah memerlukan uang untuk memenuhi kebutuhannya. Alasan klaim lainnya, untuk mencairkan (redemption) 
investasi jatuh tempo mereka, menurut Asosiasi Asuransi Jiwa Indonesia (AAJI) mencatat klaim nilai tebus atau surrender mengalami pertumbuhan $7,8 \%$ (yoy) menjadi Rp 90,76 triliun di tahun 2020. Untuk total klaim dan manfaat secara industri pada kuartal IV Tahun 2020 mencapai Rp41,49 triliun masih meningkat sebesar 5,7\% dibandingkan dengan Kuartal III Tahun 2020 di Rp39,25 triliun. Klaim meninggal dunia pada Kuartal IV Tahun 2020 meningkat sebesar 4,2\% dibandingkan dengan Kuartal III 2020, dari Rp3,30 triliun di Kuartal III 2020 menjadi Rp3,44 triliun di Kuartal IV Tahun 2020.

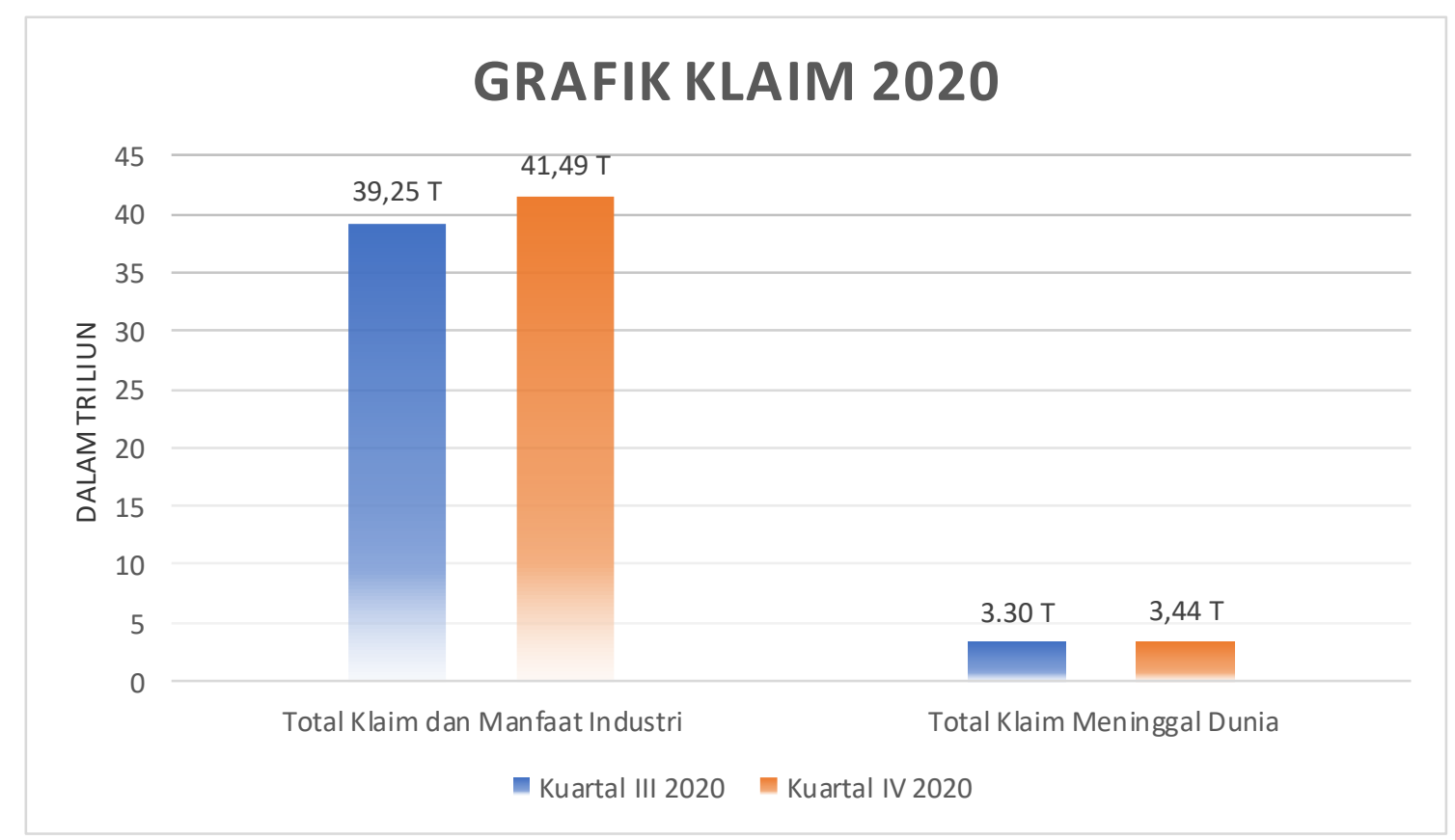

\section{Gambar 2 \\ Grafik Pertumbuhan Klaim Tahun 2020 Kuartal III dan Kuartal IV}

Klaim tersebut telah dibayarkan kepada 9,128 pemegang polis, meskipun pemerintah menyatakan bahwa Covid-19 merupakan pandemi. Komitmen industri asuransi jiwa konsisten kepada nasabah. Ketiga, terjadi peningkatan permintaan (increase in demand) seperti pada enam bulan setelah wabah sars berakhir maka terjadi peningkatan premi dua kali lipat.

Manajemen berusaha mempertahankan dan meningkatkan kinerja perusahaan dengan mengevaluasi kinerja karyawannya dimasa pandemi Covid-19 dalam penggunaan teknologi informasi. Dalam era kemajuan teknologi saat ini, peran teknologi informasi dan sistem informasi sangat penting sekali untuk menunjang kinerja sebuah perusahaan agar lebih efektif dan efisien. Teknologi informasi dan sistem informasi meruapakan sebuah cara agar perusahaan dapat meningkatkan daya saing dengan para kompetitornya, tidak sedikit perusahaan berinvestasi yang begitu besar dalam teknologi informasi dan sistem informasi. Kesuksesan pengembangan sistem informasi sangat berpengaruh pada kesesuaian dan harapan antara sistem analis dengan pengguna (user). 
Tujuan mengembangkan sistem informasi untuk meningkatkan kinerja, efiktif dan efisiensi karyawan dalam menjalankan proses bisnis yang berjalan disebuah perusahaan. Sistem informasi baik juga dapat membantu manajemen untuk mengambil keputusan karena sistem informasi dapat memberikan data secara akurat dan cepat Sehingga manajemen memutuskan untuk mengevaluasi sebuah sistem informasi E-BENEFIT. Dengan mencari tahu ketidakpuasan dari pengguna terhadap sistem tersebut seperti masih ada error bugs, butuh waktu lama saat menarik data atau mengupload dokumen kedalam sistem dan kurangnya fitur yang dibutuhkan oleh karyawan (user). Hal tersebut sangat penting karena mengingat peranan karyawan yang sangat besar dalam memberikan pelayanan dan proses bisnis perusahaan agar berjalan dengan baik untuk mendukung eksistensi perusahaan.

Dalam menerapkan suatu sistem informasi, kepuasan pengguna dapat dipengaruhi oleh kualitas sistem dan kualitas informasi yang dihasilkan (Fendini, 2013). Jika karyawan (user) sudah puas dengan sistem informasi sebagai suatu alat kerja dalam menyajikan informasi dan mempermudah proses bisnis yang ada. Kerja karyawan akan efektif dan efisien, sehingga kinerja dan pemberian pelayanan kepada nasabah tidak akan terganggu ditengah pandemi covid-19. Jika nasabah memang harus mencairkan (redemption) investasi jatuh tempo mereka, diharapkan dimasa depan dengan kondisi perekonomian yang lebih baik, nasabah akan mempercayakan lagi dengan membeli polis asuransinya di PT Asuransi Jiwa Central Asia Raya.

Suatu sistem yang sukses diimplementasikan adalah sistem yang mempunyai kinerja yang baik yang berarti bahwa sistem tersebut mempunyai kemampuan hardware dan software dalam mendukung sistem dan kemudahan dalam pemakaiannya yang berdampak pada peningkatan kinerja individu maupun organisasi (Setiono, 2016). EBENEFIT adalah sebuah sistem informasi milik PT Asuransi Jiwa Central Asia Raya untuk asuransi corporate yang digunakan oleh karyawan CAR seperti marketing untuk memberikan informasi polis asuransi kepada pemegang polis (HRD) dan peserta polis, TCM (Treasury \& Cash Management) membuat laporan dana ASO (Administrative Services Only) atau Deposit pemegang polis, CS (customer service) untuk memberikan surat penjaminan kepada nasabah, melihat manfaat apa saja yang diterima oleh Nasabah, jumlah limit klaim yang bisa digunakan dan proses penjaminan yang dilakukan oleh nasabah apakah diterima atau ditolak oleh pihak PT Asuransi Jiwa Central Asia Raya.

Penelitian inti bertujuan untuk mengetahui pengaruh kualitas sistem, kualitas informasi dan perceived usefulness yang dapat mempengaruhi kepuasan pengguna dalam menggunakan aplikasi E-BENEFIT serta pengaruh kepuasan pengguna terhadap peningkatan kinerja individu karyawan.

\section{Metode Penelitian}

Sebuah penelitian pada umumnya terdapat pendekatan dan metode penelitian yang bisa dipakai merujuk pada rumusan masalah, tujuan penelitian dan hipotesis penelitian. (Sugiyono, 2019) mengemukakan bahwa metode penelitian dapat diartikan sebagai cara 
ilmiah untuk mendapatkan data yang valid dengan tujuan dapat ditemukan, dikembangkan, dan ibuktikan, suatu pengetahuan tertentu sehingga pada gilirannya dapat digunakan untuk memahami, memecahkan, dan mengantisipasi masalah.

Penelitian ini digunakan pendekatan kuantitatif dimana masalah dan hipotesis telah ditentukan dan dijabarkan diawal, tahap selanjutnya melakukan survey dengan menyebarkan kuisioner untuk mendapatkan data serta melakukan analisis dengan statistika atau secara matematis.

Berdasarkan teori tersebut, data yang diperoleh dari sampel populasi penelitian menggunakan teknik penelitian survey. Penelitian ini dilakukan di PT AJ Central Asia Raya dengan mengambil sampel dari seluruh karyawan kantor pusat PT AJ Central Asia Raya yang menggunakan sistem aplikasi E-BENEFIT yaitu sebanyak 50 orang. Pengumpulan data melalui kuesioner yang disajikan melalui serangkaian pernyataan yang telah disusun sebelumnya dengan formulasi dan urutan tertentu yang dibagikan kepada responden sebagai sampel.

Penelitian ini menggunakan metode penelitian kuantitatif. Penelitian kuantitatif menurut (Sugiyono, 2017a), adalah metode penelitian yang berlandaskan pada filsafat positivisme, sebagai metode ilmiah atau scientific karena telah memenuhi kaidah ilmiah secara konkrit atau empiris, obyektif, terukur, rasional, dan sistematis. Metode kuantitatif bertujuan untuk menguji hipotesis yang telah ditetapkan yang digunakan untuk meneliti pada populasi maupun sampel tertentu, pengumpulan data dengan menggunakan instrument penelitian, serta analisis data yang bersifat kuantitatif atau statistik. Penelitian ini menggunakan metode penelitian kuantitatif karena penelitian ini menggunakan angka-angka dengan perhitungan statistik serta bertujuan untuk menguji hipotesis yang telah dibuat.

Penelitian ini bertujuan untuk menguji hipotesis dan menjelaskan pengaruh hubungan antara variabel-variabel, yaitu kualitas sistem, kualitas informasi, perceived usefulness terhadap kepuasan pengguna, dan kepuasan pengguna terhadap kinerja individual.

Penelitian ini menggunakan data primer yang merupakan data yang diperoleh dari responden dengan menyebarkan kuesioner untuk diisi pertanyaan yang berkaitan dengan penelitian, menurut (Sugiyono, 2017b) data primer adalah sumber data yang langsung memberikan data kepada pengumpul data.

Dalam usaha untuk mendapatkan data yang dibutuhkan metode yang digunakan adalah Kuesioner. Kuesioner dalam penelitian ini menggunakan metode Skala Likert 5 poin, Menurut (Sofyan, 2016) skala likert adalah skala yang dapat digunakan untuk mengukur sikap, pendapat dan persepsi seseorang tentang suatu objek atau fenomena tertentu. Dalam pengukuran kuesioner penelitian ini, setiap responden diminta pendapatnya mengenai suatu pernyataan yang telah dirancang sedemikian rupa untuk memperoleh data yang dibutuhkan dengan menyediakan alternatif jawaban di dalam kuesioner sehingga responden tinggal memilih salah satu jawaban yang paling sesuai. Skala penilaian dimulai dari nilai 1 dengan kondisi tanggapan negatif (minimal) sampai nilai 5 dengan kondisi tanggapan positif (maksimal). Dalam penelitian ini ada dua 
variabel yang digunakan yaitu variabel independen dan variabel dependen. Berikut penjelasannya :

1. Variabel Independen (variabel bebas)

Menurut (Sugiyono, 2017b) endefinisikan variabel independen adalah variabel yang mempengaruhi atau yang menjadi sebab perubahannya atau timbulnya variabel dependen. Dalam penelitian ini yang termasuk variabel independen adalah:

a. Kualitas Sistem (X1)

Menurut (Dwidienawati, Abdinagoro, Tjahjana, \& Gandasari, 2020) berpendapat bahwa kualitas sistem adalah integrasi fungsi sistem dan operasi sistem keandalan berdasarkan persepsi pengguna. Indikator variabel yang digunakan dalam penelitian ini diadopsi dari DeLone dan McLean dalam (Maryana, Ridhawati, \& Sayekti, 2018) dengan skala Likert 5 poin.

b. Kualitas Informasi (X2)

Kualitas informasi dapat diartikan pengukuran kualitas konten dari sistem informasi (Buana, M.M.I.B.G., dan Wirawati, 2018), Kualitas informasi secara langsung berkaitan dengan bagaimana informasi dapat digunakan dalam pengambilan keputusan untuk mencapai tujuan organisasi. Informasi yang berkualitas dapat membantu menyelesaikan tugas dengan lebih efisien dan efektif (Fitriati, Tubastuvi, \& Anggoro, 2020) Indikator variabel yang digunakan dalam penelitian ini diadopsi dari Rai et al. dalam (Utomo et al, 2017) dengan skala Likert 5 poin.

c. Perceived Usefulness (X3)

Menurut (Rukmiyati \& Mareni, 2013) mendefinisikan kemanfaatan (usefulness) sebagai suatu tingkatan dimana seseorang percaya bahwa penggunaan suatu subyek tertentu akan dapat meningkatkan prestasi kerja orang tersebut. Sedangkan menurut (Ly \& Le-Hoang, 2020) Perceived usefulness adalah bahwa seseorang percaya bahwa menggunakan sistem tertentu akan meningkatkan produktivitas kerjanya.. Indikator variabel yang digunakan dalam penelitian ini diadopsi dari (Oentario, Harianto, \& Irawati, 2017) dengan skala Likert 5 poin.

2. Variabel Dependen (variabel terikat)

Menurut (Sugiyono, 2017b) variabel dependen adalah variabel yang dipengaruhi atau yang menjadi akibat karena adanya variabel bebas. Variabel terikat dalam penelitian ini terdiri dari:

a. Kepuasan Pengguna (Y1)

Kepuasan Pengguna, adalah respon pemakai terhadap penggunaan keluaran sistem informasi (Utomo, Ardianto, \& Sisharini, 2017). Indikator variabel yang digunakan dalam penelitian ini diadopsi dari (Maryana et al., 2018) dengan skala Likert 5 poin. 
b. Kinerja Individu (Y2)

kinerja adalah sesuatu yang dilakukan atau tidak dilakukan oleh seseorang dalam memberikan kontribusi kepada organisasi (Tulodo \& Solichin, 2019) dengan skala Likert 5 poin.

\section{Hasil dan Pembahasan}

\section{A. Hasil Penelitian}

Berdasarkan hipotesis yang telah dirumuskan dalam penelitian ini agar dapat teruji, maka seharusnya perlu dilakukan suatu pengujian dengan metode statistic parametris, dimana dalam metode tersebut menyertakan bahwa dats yang akan dianalisa yang memenuhi syarat dan kriteria yang memenuhi syarat dan kriteria tersebut akan diuji dan dijabarkan di bawah ini, baik dalam menentukan tingkat valid data tersebut.

Pernyataan-pernyataan yang terkandung dalam kuisoner untuk variable Kualitas Sistem (X1), Kualitas Informasi (X2), Perceived Usefulness (X3), Kepuasan Pengguna (Y1), dan Kinerja Individu (Y2) sebagai variable yang di susun sedemikian rupa sehingga dianggap mampu memberikan masukan (input) data bagi penulis. Butir-butir pernyataan di susun dan diukur dalam skala linkert dengan bobot nilai $1-5$, yaitu dengan pernyataan-pernyataan mulai dari sangat setuju (5), setuju (4), netral (3), tidak setuju (2) dan sangat tidak setuju (1). Deskripsi hasil penelitian di peroleh berdasarkan 700 responden yang dijadikan sampel yang terdiri dari 50 orang karyawan yang menggunakan aplikasi E-BENEFIT di PT AJ Central Asia Raya.

Analisi deskriptif karakteristik responden terdiri dari table yang berisi tentang jenis kelamin, departemen tempat bekerja. Karekteristik data dikelolah berdasarkan data kuisoner secara lengkap yang dilihat.

1. Jenis Kelamin

Sebaran responden berdasarkan jenis kelamin dapat dilihat pada table berikut ini:

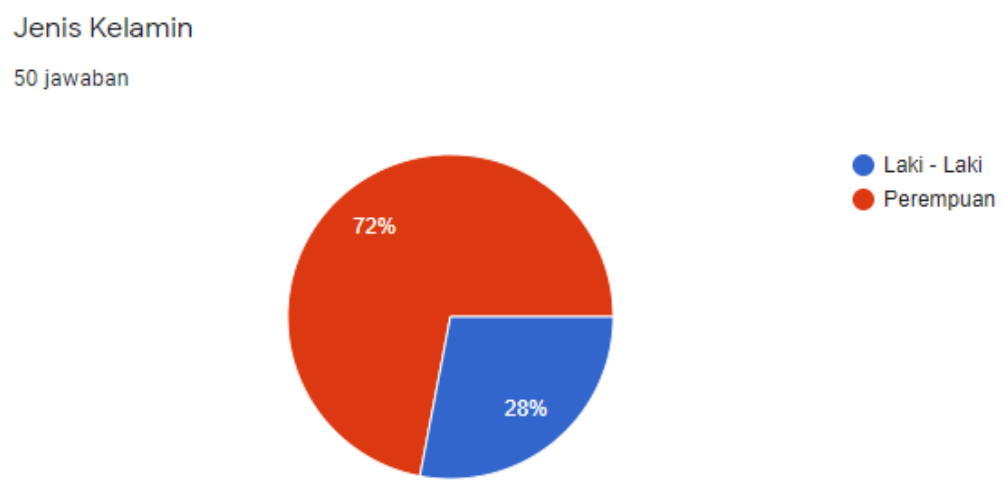

Gambar 1

Grafik Sample Berdasarkan Jenis Kelamin 
Jumlah responden terbanyak perempuan yaitu sebanyak 36 orang atau $72 \%$ dan jumlah responden laki-laki adalah 14 orang atau $28 \%$.

2. Departemen

Sebaran responden berdasarkan departemen dapat dilihat pada table berikut ini:

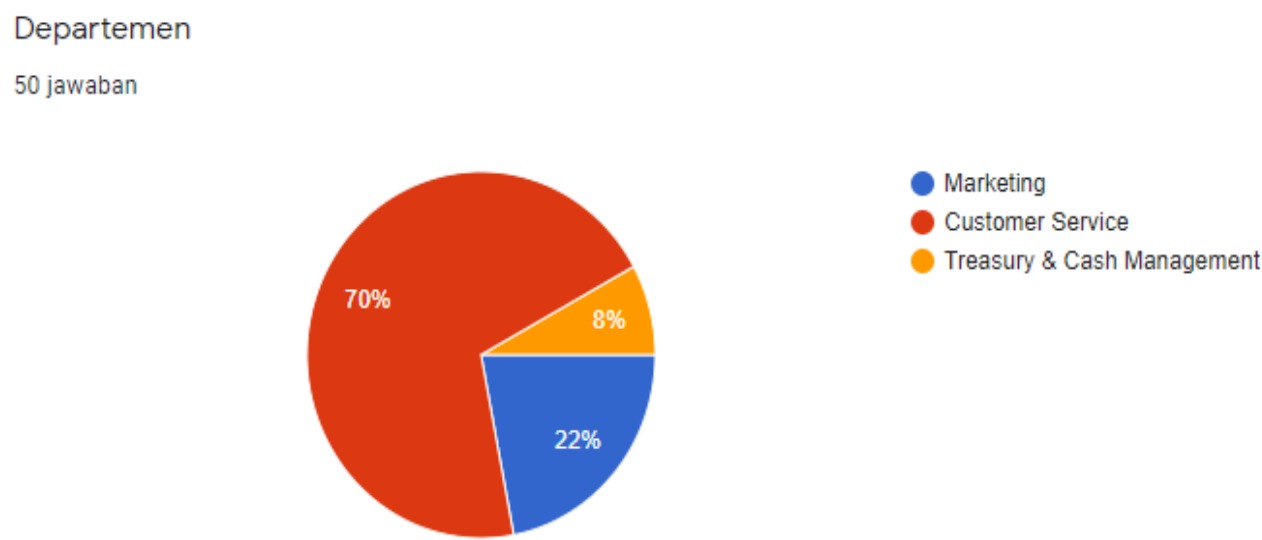

Gambar 2

Grafik Sample Berdasarkan Departemen

Jumlah responden terbanyak dari departemen Customer Service yaitu sebanyak 35 orang atau 70\%, yang kedua dari departemen marketing 11 orang atau 22\% dan jumlah responden ketiga dari departeme Treasury and Cash Management adalah 4 orang atau $8 \%$.

3. Uji Instrumen Penelitian

Pengujian validitas dan reliabilitas adalah proses menguji butir-butir penyataan yang ada dalam sebuah kuisoner, apakah isi dari butir-butir pernyataan tersebut sudah valid dan reliable, jika butir-butir pernyataan tersubut sudah valid dan reliabel berarti butir-butir pernyataan tersebut sudah bias untuk mengukur faktor-faktornya.

1) Uji Validitas

Pengujian Validitas dilakukan untuk mengetahui valid tidaknya suatu kuesioner dari masing-masing variabel tersebut. Pengujian dilakukan dengan menggunakan korelasi produk Moment Pearson, masing-masing skor pernyataan dikorelasikan dengan skor total dalam satu variabel. Metode ini menyatakan suatu pernyataan adalah valid apabila dari suatu variabel nilai $r$ hitung yang merupakan nilai dari Corrected Item-Total Correlation > dari $r$ tabel $(n-2)$. Alpha $(\alpha)$ yang dipergunakan dalam penelitian ini adalah 5\%. Keterangan :

$\mathrm{N}$ : Jumlah responden

$\alpha$ : Batas toleransi kesalahan dalam penelitian

a. Uji Validitas Variabel Kualitas Sistem (X1) 
Uji validitas kualitas sistem ini dilakukan dengan membandingkan nilai $r$ hitung dengan $\mathrm{r}$ tabel untuk $\mathrm{df}=\mathrm{n}-2$. Dalam penelitian ini $\mathrm{df}=50-2$ atau $\mathrm{df}$ $=48$ dengan $\alpha 0,05$ didapat $r$ tabel dua sisi sebesar 0,2787. Jika $r$ hitung (per item) lebih besar $r$ tabel berarti pernyataan tersebut dikatakan valid.

Tabel 1

Uji Validitas Variabel Kualitas Sistem

Item-Total Statistics

\begin{tabular}{lcrrrr}
\hline & $\begin{array}{l}\text { Scale Mean } \\
\text { if Item } \\
\text { Deleted }\end{array}$ & $\begin{array}{l}\text { Scale } \\
\text { Variance if } \\
\text { Item Deleted }\end{array}$ & $\begin{array}{l}\text { Corrected } \\
\text { Item-Total } \\
\text { Correlation }\end{array}$ & \multicolumn{2}{l}{$\begin{array}{l}\text { Cronbach's } \\
\text { Alpha if } \\
\text { Item Deleted }\end{array}$} \\
\hline $\mathrm{X} 1.1$ & 17.2600 & 7.543 & .569 & .741 \\
\hline $\mathrm{X} 1.2$ & 17.7200 & 6.369 & .567 & .725 \\
\hline $\mathrm{X} 1.3$ & 18.1800 & 6.314 & .550 & .730 \\
\hline $\mathrm{X} 1.4$ & 17.8200 & 6.069 & .663 & .698 \\
\hline $\mathrm{X} 1.5$ & 17.3600 & 7.133 & .417 & .763 \\
\hline $\mathrm{X} 1.6$ & 17.8600 & 6.858 & .413 & .767 \\
\hline \multicolumn{5}{r}{} \\
\hline
\end{tabular}

Sumber: Hasil Output SPSS v.20.0

Berdasarkan tabel 1, terlihat 6 butir pernyataan yang dinyatakan valid. Dari 6 pernyataan tersebut bahwa variabel kualitas sistem memiliki rhitung yang merupakan nilai dari Corrected Item-Total Correlation > rtabel. Analisis output kualitas sistem dapat dilihat sebagai berikut :

rhitung Pernyataan 1, dengan nilai 0,569>0,2787, dapat disimpulkan valid rhitung Pernyataan 2, dengan nilai 0,567 >0,2787, dapat disimpulkan valid rhitung Pernyataan 3, dengan nilai 0,550 >0,2787, dapat disimpulkan valid rhitung Pernyataan 4, dengan nilai 0,663 >0,2787, dapat disimpulkan valid rhitung Pernyataan 5, dengan nilai 0,417 >0,2787, dapat disimpulkan valid rhitung Pernyataan 6, dengan nilai 0,413 >0,2787, dapat disimpulkan valid.

2) Uji Validitas Variabel Kualitas Informasi (X2)

Uji validitas kualitas informasi membandingkan nilai $r$ hitung dengan $r$ tabel untuk df $=\mathrm{n}-2$. Dalam penelitian ini $\mathrm{df}=50-2$ atau $\mathrm{df}=48$ dengan $\alpha 0,05$ didapat $r$ tabel dua sisi sebesar 0,2787. Jika $r$ hitung (per item) lebih besar $r$ tabel dapat disimpulkan pernyataan tersebut dapat dikatakan valid. 
Tabel 2

Uji Validitas Variabel Kualitas Informasi (X2)

\begin{tabular}{ccccc}
\hline & $\begin{array}{c}\text { Scale Mean } \\
\text { if Item } \\
\text { Deleted }\end{array}$ & $\begin{array}{c}\text { Item-Total Statistics } \\
\text { Variance if } \\
\text { Item Deleted }\end{array}$ & $\begin{array}{c}\text { Corrected } \\
\text { Item-Total } \\
\text { Correlation }\end{array}$ & $\begin{array}{c}\text { Cronbach's } \\
\text { Alpha if } \\
\text { Item Deleted }\end{array}$ \\
\hline X2.1 & 19.0400 & 5.549 & .463 & .798 \\
\hline X2.2 & 18.9400 & 5.241 & .597 & .772 \\
\hline X2.3 & 18.9800 & 5.081 & .573 & .775 \\
\hline X2.4 & 19.1000 & 4.541 & .755 & .730 \\
\hline X2.5 & 19.1400 & 5.225 & .455 & .803 \\
\hline X2.6 & 19.2000 & 4.857 & .572 & .776 \\
\hline \multicolumn{5}{c}{ Sumber: Hasil Output SPSS v.20.0 }
\end{tabular}

Berdasarkan tabel 2, terlihat 6 butir pernyataan yang dinyatakan valid. Dari 6 pernyataan tersebut bahwa variabel kualitas informasi memiliki rhitung yang merupakan nilai dari Corrected Item-Total Correlation > rtabel.

Analisis output kualitas informasi di atas dapat dilihat sebagai berikut :

rhitung Pernyataan 1, dengan nilai 0,463>0,2787, dapat disimpulkan valid rhitung Pernyataan 2, dengan nilai $0,597>0,2787$, dapat disimpulkan valid rhitung Pernyataan 3, dengan nilai 0,573 >0,2787, dapat disimpulkan valid rhitung Pernyataan 4, dengan nilai 0,755 >0,2787, dapat disimpulkan valid rhitung Pernyataan 5, dengan nilai 0,455 >0,2787, dapat disimpulkan valid rhitung Pernyataan 6 , dengan nilai $0,572>0,2787$, dapat disimpulkan valid

3) Uji Validitas Variabel Perceived Usefulness (X3)

Uji validitas perceived usefulness membandingkan nilai $r$ hitung dengan $r$ tabel untuk $\mathrm{df}=\mathrm{n}-2$. Dalam penelitian ini $\mathrm{df}=50-2$ atau $\mathrm{df}=48$ dengan $\alpha 0,05$ didapat $r$ tabel dua sisi sebesar 0,2787. Jika $r$ hitung (per item) lebih besar $r$ tabel berarti pernyataan tersebut dapat dikatakan valid.

Tabel 3

Uji Validitas Variabel Perceived Usefulness (X3)

\begin{tabular}{lcrrr}
\hline & $\begin{array}{l}\text { Scale Mean } \\
\text { if Item } \\
\text { Deleted }\end{array}$ & $\begin{array}{l}\text { Scale } \\
\text { Variance if } \\
\text { Item Deleted }\end{array}$ & $\begin{array}{l}\text { Corrected } \\
\text { Item-Total } \\
\text { Correlation }\end{array}$ & \multicolumn{2}{l}{$\begin{array}{l}\text { Cronbach's } \\
\text { Alpha if } \\
\text { Item Deleted }\end{array}$} \\
\hline X3.1 & 19.8200 & 7.783 & .832 & .930 \\
\hline X3.2 & 19.8800 & 7.659 & .836 & .930 \\
\hline X3.3 & 19.9400 & 7.649 & .811 & .933 \\
\hline X3.4 & 19.9400 & 7.445 & .879 & .924 \\
\hline X3.5 & 19.9400 & 8.058 & .844 & .930 \\
\hline X3.6 & 20.0800 & 7.830 & .759 & .939 \\
\hline \multicolumn{5}{c}{ Sumber: Hasil Output SPSS v.20.0 }
\end{tabular}

Sumber: Hasil Output SPSS v.20.0 
Berdasarkan tabel 3, terlihat 6 butir pernyataan yang dinyatakan valid. Dari 6 pernyataan tersebut bahwa variabel perceived usefulness memiliki rhitung yang merupakan nilai dari Corrected Item-Total Correlation > rtabel. Analisis output perceived usefulness dapat dilihat sebagai berikut :

rhitung Pernyataan 1, dengan nilai 0,832>0,2787, dapat disimpulkan valid rhitung Pernyataan 2, dengan nilai 0,836 >0,2787, dapat disimpulkan valid rhitung Pernyataan 3, dengan nilai 0,811 >0,2787, dapat disimpulkan valid rhitung Pernyataan 4, dengan nilai 0,879 >0,2787, dapat disimpulkan valid rhitung Pernyataan 5, dengan nilai $0,844>0,2787$, dapat disimpulkan valid rhitung Pernyataan 6, dengan nilai 0,759>0,2787, dapat disimpulkan valid

4) Uji Validitas Variabel Kepuasan Pengguna (Y1)

Uji validitas kepuasan pengguna membandingkan nilai $r$ hitung dengan $r$ tabel untuk $\mathrm{df}=\mathrm{n}-2$. Dalam penelitian ini $\mathrm{df}=50-2$ atau $\mathrm{df}=48$ dengan $\alpha 0,05$ didapat $r$ tabel dua sisi sebesar 0,2787. Jika $r$ hitung (per item) lebih besar $r$ tabel berarti pernyataan tersebut dikatakan valid.

\section{Tabel 4}

Uji Validitas Variabel Kepuasan Pengguna (Y1) Item-Total Statistics

\begin{tabular}{lcrrr}
\hline & $\begin{array}{l}\text { Scale Mean } \\
\text { if Item } \\
\text { Deleted }\end{array}$ & $\begin{array}{l}\text { Scale } \\
\text { Variance if } \\
\text { Item Deleted }\end{array}$ & $\begin{array}{l}\text { Corrected } \\
\text { Item-Total } \\
\text { Correlation }\end{array}$ & $\begin{array}{l}\text { Cronbach's } \\
\text { Alpha if } \\
\text { Item Deleted }\end{array}$ \\
\hline Y1.1 & 15.3800 & 4.077 & .654 & .780 \\
\hline Y1.2 & 15.3600 & 3.990 & .668 & .774 \\
\hline Y1.3 & 15.5400 & 3.356 & .638 & .780 \\
\hline Y1.4 & 15.5200 & 3.847 & .649 & .775 \\
\hline Y1.5 & 15.7200 & 3.553 & .541 & .815 \\
\hline \multicolumn{5}{c}{ Sumber: Hasil Output SPSS v.20.0 }
\end{tabular}

Berdasarkan tabel 4, terlihat 5 butir pernyataan yang dinyatakan valid. Dari 5 pernyataan tersebut bahwa variabel kepuasan pengguna memiliki rhitung yang merupakan nilai dari Corrected Item-Total Correlation > rtabel.

Analisis output kepuasan pengguna dapat dilihat sebagai berikut : rhitung Pernyataan 1, dengan nilai 0,654> 0,2787, dapat disimpulkan valid rhitung Pernyataan 2, dengan nilai 0,668 >0,2787, dapat disimpulkan valid rhitung Pernyataan 3, dengan nilai 0,638 >0,2787, dapat disimpulkan valid rhitung Pernyataan 4, dengan nilai 0,649 >0,2787, dapat disimpulkan valid rhitung Pernyataan 5, dengan nilai 0,541 >0,2787, dapat disimpulkan valid

5) Uji Validitas Variabel Kinerja Individu (Y2)

Uji validitas kinerja individu membandingkan nilai $r$ hitung dengan $r$ tabel untuk df $=\mathrm{n}-2$. Dalam penelitian ini $\mathrm{df}=50-2$ atau $\mathrm{df}=48$ dengan $\alpha 0,05$ 
didapat $r$ tabel dua sisi sebesar 0,2787. Jika $r$ hitung (per item) lebih besar $r$ tabel berarti pernyataan tersebut dapat dikatakan valid.

Tabel 5

Uji Validitas Variabel Kinerja Individu (Y2)

\begin{tabular}{lcrrr}
\hline \multicolumn{5}{c}{ Item-Total Statistics } \\
\hline & $\begin{array}{c}\text { Scale Mean } \\
\text { if Item } \\
\text { Deleted }\end{array}$ & $\begin{array}{c}\text { Scale } \\
\text { Variance if } \\
\text { Item Deleted }\end{array}$ & $\begin{array}{c}\text { Corrected } \\
\text { Item-Total } \\
\text { Correlation }\end{array}$ & $\begin{array}{c}\text { Cronbach's } \\
\text { Alpha if } \\
\text { Item Deleted }\end{array}$ \\
\hline Y2.1 & 19.1800 & 5.171 & .694 & .857 \\
\hline Y2.2 & 19.4000 & 5.224 & .633 & .867 \\
\hline Y2.3 & 19.1400 & 5.102 & .612 & .872 \\
\hline Y2.4 & 19.3800 & 4.893 & .684 & .859 \\
\hline Y2.5 & 19.3000 & 5.194 & .732 & .851 \\
\hline Y2.6 & 19.2000 & 5.184 & .804 & .842 \\
\hline
\end{tabular}

Sumber: Hasil Output SPSS v.20.0

Berdasarkan tabel 5, terlihat 6 butir pernyataan yang dinyatakan valid. Dari 6 pernyataan tersebut bahwa variabel kinerja individu memiliki rhitung yang merupakan nilai dari Corrected Item-Total Correlation > rtabel.

Analisis output kinerja individu dapat dilihat sebagai berikut :

rhitung Pernyataan 1, dengan nilai 0,694>0,2787, dapat disimpulkan valid rhitung Pernyataan 2, dengan nilai 0,633 >0,2787, dapat disimpulkan valid rhitung Pernyataan 3, dengan nilai 0,612>0,2787, dapat disimpulkan valid rhitung Pernyataan 4, dengan nilai 0,684 >0,2787, dapat disimpulkan valid rhitung Pernyataan 5, dengan nilai 0,732 >0,2787, dapat disimpulkan valid rhitung Pernyataan 6, dengan nilai 0,804 >0,2787, dapat disimpulkan valid.

4. Uji Reliabilitas

Uji reliabilitas dilakukan terhadap item pertanyaan yang dinyatakan valid. Suatu variabel dikatakan reliabel atau handal jika jawaban terhadap pertanyaan selalu konsisten. Untuk menilai sebuah pertanyaan reliabel dapat dilihat dari nilai Cronbach alpha pada setiap pertanyaan. Suatu pernyataan dinyatakan reliable jika mempunyai nilai Cronbach alpha $>0,60$.

1) Uji Reliabilitas Variabel Kualitas Sistem (X1)

\section{Tabel 6}

Uji Validitas Variabel Kualitas Sistem (X1)

Reliability Statistics
Cronbach's N of Items

Alpha

$.772 \quad 6$

Sumber : Hasil Output SPSS v.20.0 
Tabel 6 menunjukan tabel Reliability Statistics yang menunjukan suatu variabel dikatakan reliabel atau handal jika jawaban terhadap pertanyaan selalu konsisten dan Croncbach`s Alpha 0,772 > 0,60. Dapat disimpulkan bahwa pernyataan-pernyataan dalam variabel kualitas sistem adalah reliabel, artinya adalah bahwa hasil pengukuran variabel kualitas sistem adalah reliabel.

2) Uji Reliabilitas Variabel Kualitas Informasi (X2)

\section{Tabel 7}

Uji Validitas Variabel Kualitas Informasi (X2)

\begin{tabular}{l}
\multicolumn{2}{c}{ Reliability Statistics } \\
Cronbach's \\
Alpha \\
\hline \multicolumn{2}{r}{ N of Items } \\
\hline
\end{tabular}

Sumber : Hasil Output SPSS v.20.0

Tabel 7 menunjukan tabel Reliability Statistics yang menunjukan suatu variabel dikatakan reliabel atau handal jika jawaban terhadap pertanyaan selalu konsisten dan Croncbach`s Alpha 0,807 > 0,60. Dapat disimpulkan bahwa pernyataan-pernyataan dalam variabel kualitas informasi adalah reliabel, artinya adalah bahwa hasil pengukuran variabel kualitas informasi adalah reliabel.

3) Uji Reliabilitas Variabel Perceived Usefulness (X3)

\section{Tabel 8}

Uji Validitas Variabel Perceived Usefulness

\begin{tabular}{c}
$\frac{\text { Reliability Statistics }}{\text { Cronbach's Alpha N of Items }}$ \\
\hline .942 \\
\hline Sumber : Hasil Output SPSS v. 20.0
\end{tabular}

Tabel 8 menunjukan tabel Reliability Statistics yang menunjukan suatu variabel dikatakan reliabel atau handal jika jawaban terhadap pertanyaan selalu konsisten dan Croncbach`s Alpha 0,942 > 0,60. Dapat disimpulkan bahwa pernyataan-pernyataan dalam variabel perceived usefulness adalah reliabel, artinya adalah bahwa hasil pengukuran variabel perceived usefulness adalah reliabel. 
4) Uji Reliabilitas Variabel Kepuasan Pengguna (Y1)

\section{Tabel 9}

Uji Validitas Variabel Kepuasan Pengguna (Y1)

\begin{tabular}{l}
\hline \multicolumn{2}{c}{ Reliability Statistics } \\
Cronbach's N of Items \\
Alpha \\
\hline \multicolumn{2}{r}{.820} & 5 \\
\hline
\end{tabular}

Sumber : Hasil Output SPSS v.20.0

Tabel 9 menunjukan tabel Reliability Statistics yang menunjukan suatu variabel dikatakan reliabel atau handal jika jawaban terhadap pertanyaan selalu konsisten dan Croncbach`s Alpha 0,820 > 0,60. Dapat disimpulkan bahwa pernyataan-pernyataan dalam variabel kepuasan pengguna adalah reliabel, artinya adalah bahwa hasil pengukuran variabel kepuasan pengguna adalah reliabel.

5) Uji Reliabilitas Variabel Kinerja Individu (Y2)

Tabel 10

Uji Validitas Variabel Kinerja Individu (Y2)

\section{Reliability Statistics}

Cronbach's N of Items

Alpha

$\frac{.879}{\text { Sumber : Hasil Output SPSS v.20.0 }}$

Tabel 10 menunjukan tabel Reliability Statistics yang menunjukan suatu variabel dikatakan reliabel atau handal jika jawaban terhadap pertanyaan selalu konsisten dan Croncbach`s Alpha 0,879 > 0,60. Dapat disimpulkan bahwa pernyataan-pernyataan dalam variabel kinerja individu adalah reliabel, artinya adalah bahwa hasil pengukuran variabel kinerja individu adalah reliabel.

\section{Uji Asumsi Klasik}

Uji asumsi klasik dilakukan untuk mengukur apakah variabel-variabel yang akan diteleiti dapat disebut sebagai variabel yang baik jika variabel tersebut memenuhi asumsi normalitas data dan terbebas dari asumsi klasik statistik.

1) Uji Normalitas

Hasil uji normalitas dapat terlihat dengan pendekatan Kolmogorovsmirnov. Sebelumnya, peneliti menentukan besarnya variabel residual dengan menggunakan bantuan SPSS. Setelah didapatkan residualnya, maka berikut ini adalah uji kolmogorov-smirnov. 
Tabel 11

Uji Kolmogorov Smirnov Persamaan Satu

One-Sample Kolmogorov-Smirnov Test

Unstandardi

zed Residual

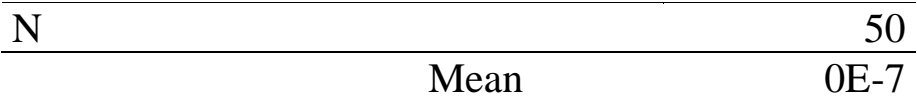

\begin{tabular}{llr} 
Normal Parameters $^{\mathrm{a}, \mathrm{b}}$ & Mean & 0E-7 \\
\cline { 2 - 3 } & $\begin{array}{l}\text { Std. } \\
\text { Deviation }\end{array}$ & 1.15270609
\end{tabular}

\begin{tabular}{llr}
\hline \multirow{2}{*}{$\begin{array}{l}\text { Most Extreme } \\
\text { Differences }\end{array}$} & Absolute & .127 \\
\cline { 2 - 3 } & Positive & .088 \\
\cline { 2 - 3 } & Negative & -.127 \\
\hline Kolmogorov-Smirnov Z & .895 \\
\hline Asymp. Sig. (2-tailed) & .400 \\
\hline
\end{tabular}

a. Test distribution is Normal.

b. Calculated from data.

Sumber : Hasil Output SPSS v.20.0

Berdasarkan tabel 11 diatas, Asymp. Sig (2-tailed) sebesar 0,400>0,05 maka dapat dinyatakan data residual pada penelitian ini berdistribusi normal.

Hasil uji normalitas dapat terlihat dengan pendekatan kolmogorovsmirnov. Sebelumnya, peneliti menentukan besarnya variabel residual dengan menggunakan bantuan SPSS. Setelah didapatkan residualnya, maka berikut ini adalah uji kolmogorov-smirnov.

Tabel 12

Uji Kolmogorov Smirnov Persamaan Dua

\begin{tabular}{llr}
\hline \multicolumn{3}{c}{ One-Sample Kolmogorov-Smirnov Test } \\
\hline & $\begin{array}{r}\text { Unstandardi } \\
\text { zed Residual }\end{array}$ \\
\hline $\mathrm{N}$ & Mean & 50 \\
\cline { 2 - 3 } Normal Parameters & $\begin{array}{l}\text { Std. } \\
\text { Deviation }\end{array}$ & 1.39475957 \\
\hline Most Extreme & Absolute & .191 \\
\cline { 2 - 3 } Differences & Positive & .191 \\
\cline { 2 - 3 } & Negative & -.181 \\
\hline Kolmogorov-Smirnov Z & 1.352 \\
\hline Asymp. Sig. (2-tailed) & .052 \\
\hline \multicolumn{2}{l}{ a. Test distribution is Normal. } \\
\hline b. Calculated from data. \\
\hline \multicolumn{2}{c}{ Sumber : Hasil Output SPSS v.20.0 } \\
\hline
\end{tabular}

Berdasarkan tabel 12 diatas, Asymp. Sig (2-tailed) sebesar 0,052> 0,05 maka dapat dinyatakan data residual pada penelitian ini berdistribusi normal. 
2) Uji Multikolinieritas

Uji multikolinearitas berfungsi untuk menguji apakah model regresi ditemukan adanya korelasi antar varibel bebas (independent variabel). Pada model regresi ini dikatakan baik jika tidak terjadi korelasi yang sempurna atau mendekati antar variabel independent. Dasar pengambilan keputusan ini jika nilai Tolerance $>0,1$ dan nilai VIF (Variance Inflation Factor) $<10$, maka model regresi ini dapat disimpulkan terbebas dari multikolinearitas.

Tabel 13

Uji Multikonlinieritas Persamaan Saturday

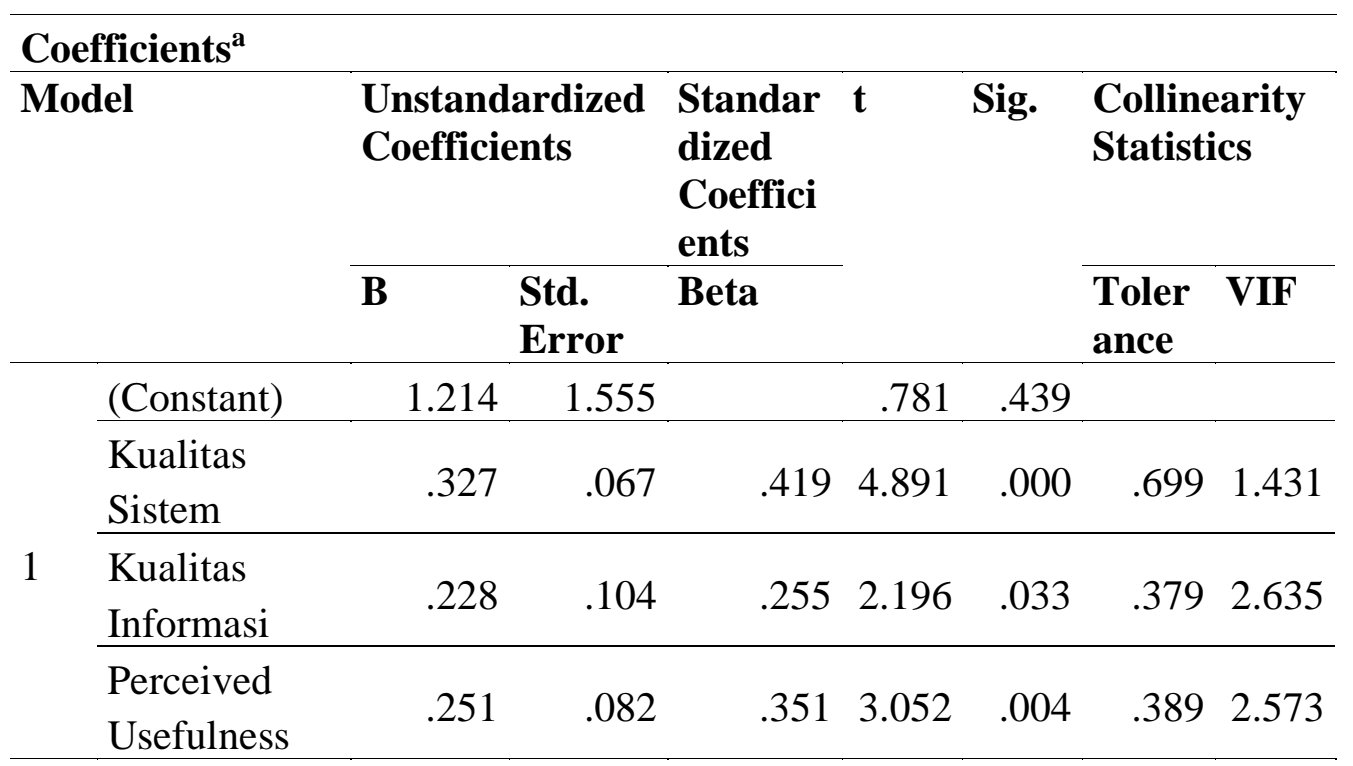

a. Dependent Variable: Kepuasan Pengguna

Sumber : Hasil Output SPSS v.20.0

Tabel 13 Hasil uji multikolinearitas persamaan satu Menunjukan setiap variabel independen mempunyai tolerance lebih dari 0,1 dan VIF kurang dari 10, sebagai berikut :

1) Kualitas Sistem : Tolerance 0,699 > 0.1, VIF 1,431 < 10

2) Kualitas Informasi : Tolerance $0,379>0.1$, VIF $2,635<10$

3) Perceived Usefulness : Tolerance 0,389 > 0,1, VIF 2,573<10

Maka dapat dinyatakan model regresi pada penelitian ini tidak terjadi atau terbebas dari multikolinearitas. 
Tabel 14

Uji Multikolinieritas Persamaan Dua

\begin{tabular}{|c|c|c|c|c|c|c|c|}
\hline \multicolumn{8}{|c|}{ Coefficients $^{\mathrm{a}}$} \\
\hline \multirow{2}{*}{\multicolumn{2}{|c|}{ Model }} & $\begin{array}{l}\text { Unstand } \\
\text { Coefficie }\end{array}$ & $\begin{array}{l}\text { ardized } \\
\text { ents }\end{array}$ & $\begin{array}{l}\text { Standar } \\
\text { dized }\end{array}$ & $\mathbf{t}$ & Sig. & $\begin{array}{l}\text { Collinearity } \\
\text { Statistics }\end{array}$ \\
\hline & & $\mathbf{B}$ & $\begin{array}{l}\text { Std. } \\
\text { Error }\end{array}$ & Beta & & & $\begin{array}{ll}\text { Toler } & \text { VIF } \\
\text { ance } & \end{array}$ \\
\hline \multirow[b]{2}{*}{1} & (Constant) & 4.377 & 1.657 & & 2.642 & .011 & \\
\hline & $\begin{array}{l}\text { Kepuasan } \\
\text { Pengguna }\end{array}$ & .967 & .085 & .855 & $\begin{array}{r}11.39 \\
7\end{array}$ & .000 & 1.0001 .000 \\
\hline
\end{tabular}

a. Dependent Variable: Kinerja Individu

Sumber : Hasil Output SPSS v.20

Tabel 14 hasil uji multikolinearitas persamaan dua menunjukan setiap variabel independen mempunyai tolerance lebih dari 0,1 dan VIF kurang dari 10, sebagai berikut :

1) Kepuasan Pengguna : Tolerance $1,000>0,1$, VIF 1,000<10 Maka dapat dinyatakan model regresi pada penelitian ini tidak terjadi atau terbebas dari multikolinearitas.

3) Uji Heteroskedastisitas

Deteksi heterokedastisitas dapat dilakukan dengan metode scatter plot dengan memplotkan nilai ZPRED (nilai prediksi) dengan SRESID (nilai residualnya). Berdasarkan grefik scatter plot pada gambar dibawah ini, dasar pengambilan keputusan adalah jika titik-titik pada gambar tersebut tidak membentuk pola tertantu seperti garis lurus, bergelombang atau titik-titik berkumpul pada area tertentu maka dapat disimpulkan tidak terjadi heteroskedastisitas.

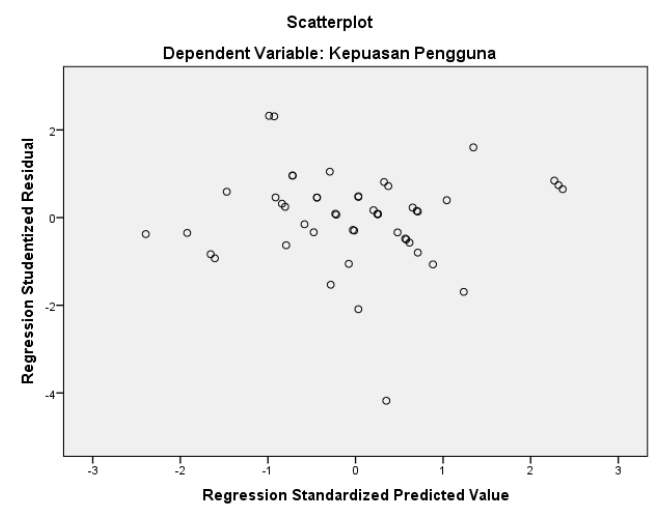

Sumber: Hasil Output SPSS v.20.0

Gambar 1

Uji Heteroskedastisitas Scatterplot Persamaan Satu 
Gambar 1 hasil output SPSS Scatterplot menunjukkan bahwa titik-titik pada gambar menyebar dan tidak membentuk pola tertentu. Jadi data pada penelitian ini tidak terdapat heteroskedastisitas.

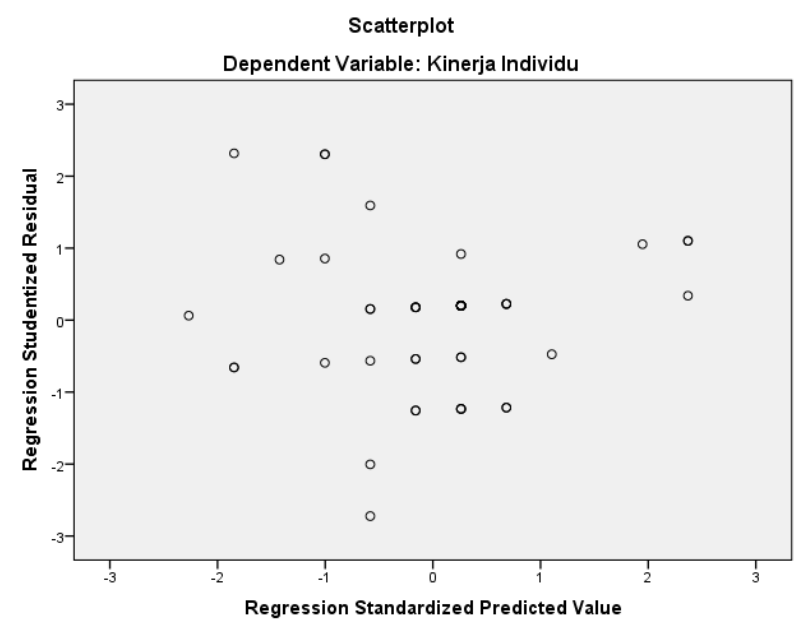

Sumber: Hasil Output SPSS v.20.0

Gambar 2

Uji Heteroskedastisitas Scatterplot Persamaan Dua

Gambar 2 hasil output SPSS Scatterplot menunjukkan bahwa titik-titik pada gambar menyebar dan tidak membentuk pola tertentu. Jadi data pada penelitian ini tidak terdapat heteroskedastisitas.

\section{Kesimpulan}

Tesis ini disusun dengan tujuan untuk mengetahui apakah variable kualitas sistem, kualitas informasi, perceived usefulness mempunyai pengaruh terhadap kepuasan pengguna dan kepuasan pengguna berpengaruh terhadap kinerja individu karyawan PT Asuransi Jiwa Central Asia Raya, maka dapat dianalisa sebagai berikut: (1.) Pengujian kualitas sistem memperoleh hasil yang menyatakan bahwa kualitas sistem memiliki hubungan yang positif terhadap kepuasan pengguna aplikasi E-BENEFIT. Sehingga dapat diartikan bahwa aplikasi E-BENEFIT sudah memiliki sistem yang berkualitas yang cukup dari indicator kemudahaan penggunaan aplikasi, akses yang cepat saat menggunakan aplikasi, keamanan aplikasi hingga integritas antara aplikasi E-BENEFIT dengan aplikasi yang lainnya. (1.) Pengujian kualitas informasi diperoleh hasil yang menyatakan bahwa kualitas informasi memiliki hubungan yang positif terhadap kepuasan pengguna aplikasi E-BENEFIT. Sehingga dapat diartikan bahwa aplikasi EBENFIT sudah memberikan informasi yang berkualitas, dari sisi penyajian informasi yang nudah dipahami, keakuratan data yang dihasil hingga ketepatan waktu yang masih tergolong cukup untuk memenuhi kebutuhan pengguna. (2.) Pengujian perceived usefulness diperoleh hasil yang menyatakan bahwa perceived usefulness memiliki hubungan yang positif terhadap kepuasan pengguna aplikasi E-BENEFIT. Sehingga dapat diartikan bahwa pengguna aplikasi E-BENEFIT merasakan kemanfaatannya dan 
lebih efektif dalam membantu menyelesaikan pekerjaanya. (3.) Pengujian kepuasan pengguna diperoleh hasil yang menyatakan bahwa kepuasan pengguna aplikasi EBENEFIT memiliki hubungan yang positif terhadap kinerja individu. Sehingga dapat diartikan bahwa kepuasaan dalam menggunakan aplikasi E-BENEFIT berdampak pada meningkatnya kinerja individu, karena pengguna aplikasi E-BENEFIT mendapatkan efisiensi dan efektifitias dalam menyelesaikan pekerjaannya menjadi lebih cepat dan hasil dari pekerjaannya memiliki kualitas dan kuantitas yang baik. 


\section{BIBLIOGRAFI}

Buana, M.M.I.B.G., dan Wirawati, N. G. P. (2018). Pengaruh Kualitas Sistem Informasi, Kualitas Informasi, dan Perceived Usefulness pada Kepuasan Pengguna Sistem Informasi Akuntansi. E-Jurnal Akuntansi Universitas Udayana, 22.(1), 683-713.

Dwidienawati, Diena, Abdinagoro, Sri Bramatoro, Tjahjana, David, \& Gandasari, Dyah. (2020). Forced shifting to e-learning during the covid-19 outbreak: Information quality, system quality, service quality, and goal orientation influence to e-learning satisfaction and perceived performance. International Journal of Advanced Trends in Computer Science and Engineering, 1518-1525. Google Scholar

Fendini, Dian Septiayu. (2013). Pengaruh Kualitas Sistem dan Kualitas informasi terhadap Kepuasan Pengguna (Survei Pada Karyawan Pengguna Aplikasi Pelayanan Pelanggan Terpusat (AP2T) di PT. PLN (Persero) Area Malang). Jurnal Administrasi Bisnis, 4(1). Google Scholar

Fitriati, Azmi, Tubastuvi, Naelati, \& Anggoro, Subuh. (2020). The Role of AIS Success on Accounting Information Quality. Int. J. Bus. Manag. Technol, 4(2), 43-51. Google Scholar

LY, Nguyen Thi Huong, \& Le-Hoang, Phuong Viet. (2020). The Effects Of Perceived Usefulness, Positive Online Customer Review, Brand Image, Price On Purchase Intention: The Case Of Online Hotel Booking. International Journal of Management (IJM), 11(6). Google Scholar

Maryana, Ferra, Ridhawati, Rakhmi, \& Sayekti, Tuti Arum. (2018). Pengaruh Kualitas Sistem Dan Kualitas Informasi Terhadap Kepuasan Pengguna Aplikasi Pelayanan Pelanggan Terpusat (Ap2t) Pt Pln (Persero) Wilayah Kalimantan Tengah Dan Kalimantan Selatan Area Barabai. Dinamika Ekonomi-Jurnal Ekonomi Dan Bisnis, 11(2), 213-229. Google Scholar

Oentario, Yudianto, Harianto, Agung, \& Irawati, Jenny. (2017). Pengaruh Usefulness, Ease of Use, Risk Terhadap Intentionto Buy Onlinepatisserie Melalui Consumer Attitude Berbasis Media Sosial Di Surabaya. Jurnal Manajemen Pemasaran, 11(1), 26-31. Google Scholar

Rukmiyati, Ni Made Sri, \& Mareni, Ni Ketut. (2013). Pengaruh Kualitas Sistem Informasi Dan Perceived Usefulness Pada Kepuasan Pengguna Akhir Software Akuntansi Hotel Bintang Lima. Jurnal Bisnis Hospitaliti, 2(1), 53-61. Google Scholar

Setiono, Kharisma Ramadhani Zakhia. (2016). Pengaruh Kualitas Sistem Dan Kualitas Layanan Sistem Informasi Akuntansi Berbasis Komputer Terhadap Kepuasan Pengguna:(Studi Pada Perusahaan Bumn yang Berkantor Pusat di Kota Bandung). Universitas Pendidikan Indonesia. Google Scholar 
Sofyan, Siregar Ir. (2016). Statistika Deskriptif untuk penelitian dilengkapi Perhitungan Manual dan Aplikasi SPSS Versi 17, Ed. I. Cet. II. Google Scholar

Sugiyono. (2017a). Metode Penelitian Kuantitatif, Kualitatif, dan R\&D. Bandung: Alfabeta Surya. Google Scholar

Sugiyono. (2017b). Metode Penelitian Kulitatif Kuantitatif. Jakarta: Alfabeta. Google Scholar

Sugiyono. (2019). Metode Penelitian Kuantitatif, kualitatif dan R\&D. Bandung: Alfabeta. Google Scholar

Tulodo, Bernadeta Asri Rejeki, \& Solichin, Achmad. (2019). Analisis Pengaruh Kualitas Sistem, Kualitas Informasi dan Perceived Usefulness terhadap Kepuasan Pengguna Aplikasi Care dalam Upaya Peningkatan Kinerja Karyawan. JRMSIJurnal Riset Manajemen Sains Indonesia, 10(1), 25-43. Google Scholar

Utomo, Listanto Tri, Ardianto, Yusaq Tomo, \& Sisharini, Nanik. (2017). Pengaruh kualitas sistem, kualitas informasi, kualitas layanan, terhadap kepuasan pengguna sistem informasi akademik universitas merdeka malang. Jurnal Teknologi Dan Manajemen Informatika, 3(2). Google Scholar

\section{Copyright holder:}

Bugi Tri Harso, Dino Arletta, Kusumo Adi (2021)

\section{First publication right:}

Syntax Idea

This article is licensed under:

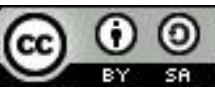

